\title{
The Pectoralis Major Myocutaneous Pedicled Flap Revisited*
}

\author{
Shinichi Asamura ${ }^{1 \#}$, Hirohiko Kakizaki ${ }^{2}$, Kazunori Mori ${ }^{3}$, \\ Kazuhide Matsunaga ${ }^{4}$, Mitsuhiro Wada ${ }^{1}$, Noritaka Isogai ${ }^{1}$ \\ ${ }^{1}$ Department of Plastic and Reconstructive Surgery, Kinki University Faculty of Medicine, Osaka, Japan \\ ${ }^{2}$ Department of Ophthalmology, Aichi Medical University, Nagakute, Japan \\ ${ }^{3}$ Department of Otolaryngology, Kinki University Faculty of Medicine, Osaka, Japan \\ ${ }^{4}$ Department of Oral and Maxillofacial Surgery, Field of Maxillofacial Rehabilitation Advanced Therapeutic Course, Kagoshima \\ University Graduate School of Medical and Dental Sciences, Kagoshima, Japan \\ Email: \#asamura@med.kindai.ac.jp
}

Received June 11, 2013; revised July 13, 2013; accepted July 20, 2013

Copyright (C) 2013 Shinichi Asamura et al. This is an open access article distributed under the Creative Commons Attribution License, which permits unrestricted use, distribution, and reproduction in any medium, provided the original work is properly cited.

\begin{abstract}
The pectoralis major myocutaneous pedicle flap (PMMF) is still being used by many surgeons and plays an important role in head and neck reconstruction. The purpose of this series was to review our 10 years' experience with the PMMF in head and neck reconstruction. One hundred and two patients who underwent the PMMF technique were reviewed on the clinical records. Postoperative complications were classified into flap loss, hemorrhage, infection, fistula formation, wound dehiscence and donor site complication. Eighty two patients (80.4\%) demonstrated no complication. Six patients among 102 patients $(5.9 \%)$ demonstrated total or partial skin necroses. Three female patients were completely dissatisfied with the cosmetic appearance after the PMMF. One of them required a reconstructive surgery with the latissimusdorsi flap. Without surgical expertise in plastic surgical field, an ear-nose-throat or an oral surgeon can performed the PMMF technique provided the operator is well aware of serious and frequent complications of this "workhorse" procedure.
\end{abstract}

Keywords: Pectoralis Major Myocutaneous Pedicled Flap; Head and Neck Reconstruction; Flap Loss; Breast Disfigurement

\section{Introduction}

The pectoralis major myocutaneous pedicle flap (PMMF) is still being employed by many surgeons and plays an important role in head and neck reconstruction [1-5]. As for the technique of harvesting the PMMF, the skin island needs to be designed principally medial to and at the level of the nipple. The pectoralis major muscle is free from the underlying chest wall, subsequently a subcutaneous tunnel is created into the defect through which the PMMF is passed to the claviclar area (Figure 1) [1].

An ear-nose-throat surgeon or an oral surgeon uses this technique because of its simplicity and less time consuming. Nevertheless, the surgeon who prefers the free flap believes that it not only achieves better functional and cosmetic results, but also has fewer donor-site morbidities, flap necrosis, fistula formation and others

\footnotetext{
*Conflict of Interest Statement: No conflicting relationship exists for any authors.

\#Corresponding author.
}

[6-12].

We, therefore, examined complications of the PMMF technique based on our surgical experience.

\section{Patients and Methods}

One hundred and two patients who underwent the PMMF were reviewed on the clinical records from January 2003 to March 2013 at the department of Plastic Surgery, Kinki University School of Medicine.All the surgeries were operated by the single surgeon (SA). The outline of this technique was shown in the Figure 1. Postoperative complications were classified into flap loss, hemorrhage, infection, fistula formation, wound dehiscence and donor site complication. The operative sites were in 1) oral cavity 2) oropharynx 3) larynx/hypopharynx 4) esophagus 5) cutaneous neck 6) parotid (Table 1). Those patients with the above $1-4$ areas, were also evaluated swallowing function using video fluorography one month after the operation (Figure 2) [13,14]. 

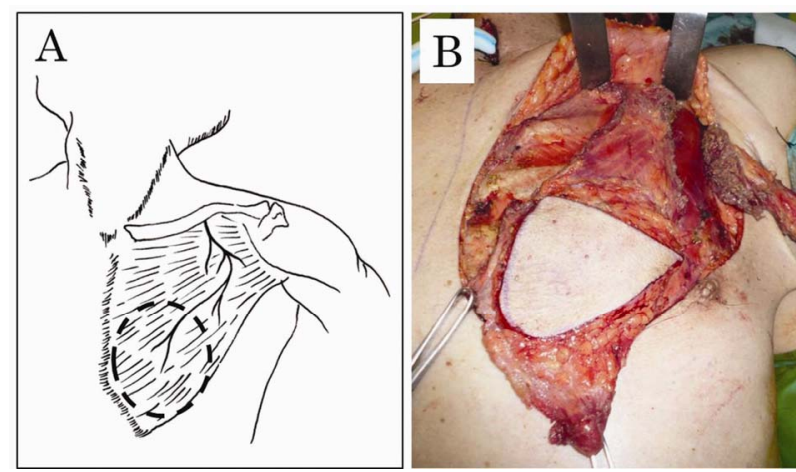

Figure 1. The PMMF technique. (a) The designof the skin island (shown within the dotted circle); (b) An elevated PMMF.

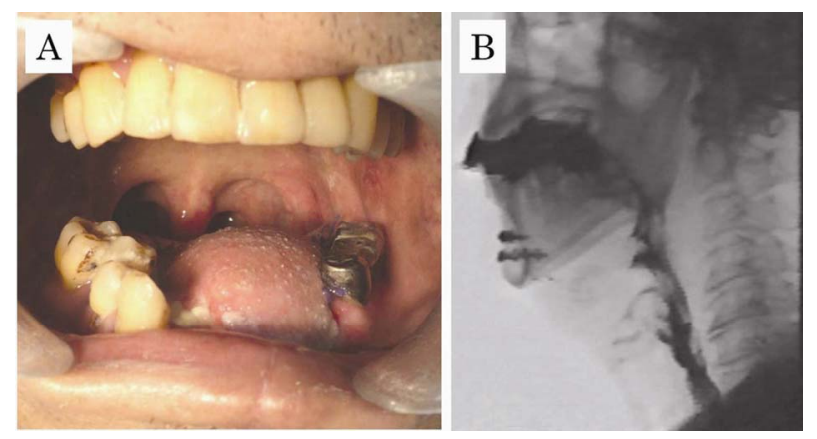

Figure 2. (a) The post-operative photos. After 6 months; (b) Swallowing function using video fluorography.

Table 1. Site of primary tumor.

\begin{tabular}{cc}
\hline Site of defects & Cases \\
\hline Oral cavity & $51(50)$ \\
Oropharynx & $4(3.9)$ \\
Larynx/hypopharynx & $17(16.7)$ \\
Partoid & $6(5.9)$ \\
Cutaneous neck & $12(11.8)$ \\
Cervical esophagus & $12(11.8)$ \\
Total & $102(100)$ \\
\hline
\end{tabular}

\section{Result}

In the 102 patients, there were 78 male (mean age 63 years old; age range 27 - 82), and 24 female (mean age 62 years old; age range $23-78)$. The average age of the total patients was 63 years. Fifty nine patients $(57.8 \%)$ had a smoking habit which is serious risk factors of a flap loss. All patients were diagnosed to have malignant lesions within the head and neck regions and the resection of each tumor were performed. Location of the selesion was listed in the Table 1. The PMMF was applied to the left side of 59 patients and the right side of 43 patients.
The PMMF was performed as a salvage purpose for 7 patients with unsuccessful previous operations, in which 2had lost rectus abdominis myocutaneous flap. Ninety eight patients $(97.4 \%)$ received a radiation therapy before or after the PMMF technique. Twenty patients $(19.6 \%)$ received preoperative radiation, and 78 patients $(76.8 \%)$, postoperatively.

Eighty two patients $(80.4 \%)$ demonstrated no complication. In view of the gender difference, 64 male $(82.0 \%)$ and 18 female $(75.0 \%)$ showed unremarkable post-operative course. Both total and partial skin necrosis was shown in 3 cases $(2.9 \%)$ in each group. One male patient $(1.0 \%)$ and 2 female patients $(2.0 \%)$ demonstrated total skin necroses (Figure 3). Two males (2.0\%) and 1 female $(1.0 \%)$ demonstrated partial skin necroses. Postoperative hemorrhage, and infection in the recipient sites were shown in female case. Five male patients $(4.9 \%)$ showed fistula formation, and one male patient $(1.0 \%)$ illustrated a wound dehiscence (Table 2). There were total three complications of the donor site. Even though there were none of the complications like wound dehiscence, hematoma, or wound abscess, there were 3 female patients who were completely dissatisfied with their breast appearance (Figure 4). One of them required a reconstructive surgery with the latissimusdorsi flap. On the contrary, there is no cosmetic complains among male patients.
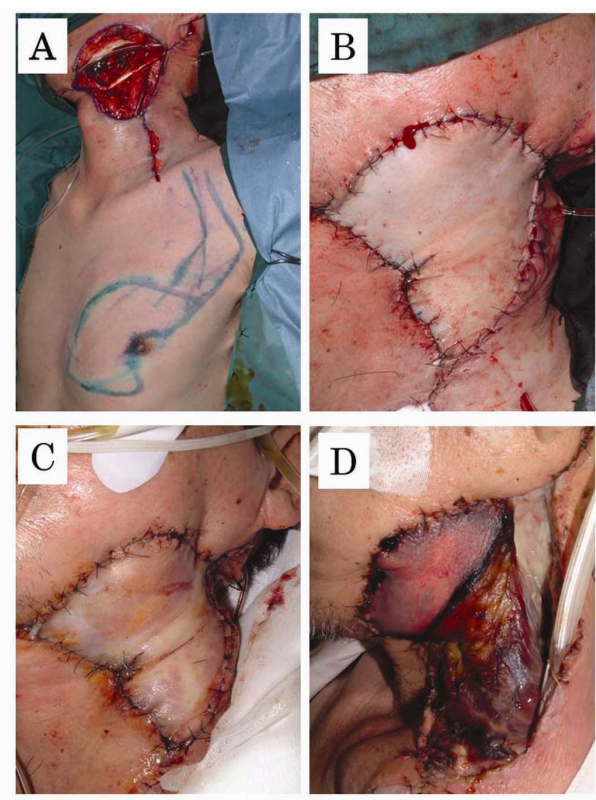

Figure 3. One example of the total skin necrosis after the PMMF technique. (a) The design of the skin island made over the pectoralis major muscle; (b) Immediately after the elevation of the flap, the color of the flap skin appeared to be slightly pale; (c) On the 1st post-operative day, the skin was discolored to become in purple color; (d) On the 7th post-operative day, the necrosis of the skin and subcutaneous tissue became apparent. 


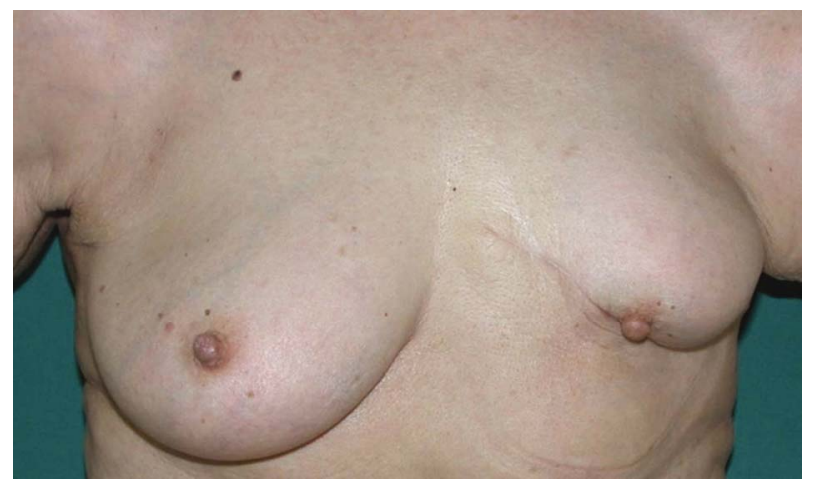

Figure 4. One example of the breast disfigurement after the PMMF technique.

Table 2. List of the complications.

\begin{tabular}{ccc}
\hline Complication & No. of flaps & $\%$ \\
\hline Total flap necrosis & 0 & 0 \\
Skin necrosis (total) & 3 & 2.9 \\
Skin necrosis (partial) & 3 & 2.9 \\
Secondary hemorrhange & 1 & 1 \\
Recipient site infection & 1 & 1 \\
Fistula formatuion & 5 & 4.9 \\
Dehiscence & 2 & 2 \\
Donor region comlication & 3 & 2.9 \\
Total & 20 & 19.6 \\
No complication & 82 & 80.4 \\
\hline
\end{tabular}

Table 3. The quoted reports between 2003 and 2013.

\begin{tabular}{|c|c|c|c|c|c|}
\hline $\begin{array}{l}\text { Previous report, } \\
\text { first author (y) }\end{array}$ & $\begin{array}{c}\text { No. of } \\
\text { Flaps }\end{array}$ & $\begin{array}{c}\text { Overall } \\
\text { complication } \\
(\%)\end{array}$ & $\begin{array}{c}\text { Skin total } \\
\text { necrosis (\%) }\end{array}$ & $\begin{array}{c}\text { Skin } \\
\text { partical } \\
\text { necrosis } \\
(\%)\end{array}$ & $\begin{array}{c}\text { Fistula } \\
(\%)\end{array}$ \\
\hline Liu (2001) & 224 & 34.8 & 4 & 11.1 & 7.8 \\
\hline Dedivitis (2002) & 17 & 41.2 & 5.9 & 5.9 & 11.8 \\
\hline Vartanian (2004) & 371 & 36.1 & 2.4 & 9.7 & 11.8 \\
\hline Milenovic (2006) & 467 & N.A. & 4.1 & 7.1 & 6 \\
\hline $\begin{array}{c}\text { Ramakrishnan } \\
\text { (2009) }\end{array}$ & 76 & N.A. & 2.6 & 1.3 & N.A. \\
\hline Mclean (2010) & 139 & 13 & 0.7 & 2.9 & 13 \\
\hline Current study & 102 & 19.6 & 2.9 & 2.9 & 4.9 \\
\hline
\end{tabular}

\section{Discussion}

The most serious disadvantage of the PMMF technique is frequently an aesthetic disfigurement of the breasts for female patients. When the skin island is designed from the medial margin of the areola, the flap contains rich subcutaneous tissue and mammary glands. It is usually very bulky and, a breast deformity is often shown. Regarding the breast disfigurement, 3 female patients were completely dissatisfied with the cosmetic appearance after the PMMF. One of them required a reconstructive surgery with the latissimusdorsi flap one year after the primary operation (Figure 4). The operative plan needs be settles including a cosmetic appearance of the donor site, in addition to the primary construction area.

The skin island must be designed, including the third intercostal perforating branch of the internal thoracic artery. This method made it possible to use a small and thin flap [15]. However, if a case requires a large skin island, which must contain adequate blood supply, it must include the inner margin of the breast tissue. It is obvious that the larger skin island is employed, more deformity is expected on the breast postoperatively. The PMMF technique for female patients need to be, therefore, limited to only small defect repair.

Although the PMMF technique has got popularity after the original report of Ariyan, some surgeons reported disadvantage of this technique [4,7]. The major ones were unstable vascular circulation in the skin island, a partial necrosis tendency in comparison with the free flaps [16].

The others reported that relatively large and clinically important perforating branch of the $4^{\text {th }}$ intercostal vessel locating $2-3 \mathrm{~cm}$ medial to the nipple supplies adequate blood flow to the skin flap [17]. It is important to have an adequate size of a skin island of the PMMF with least 90 $\%$ or more, skin area directly on the pectoralis muscle. This design contains the $4^{\text {th }}$ intercostal branch vessels within the skin island.

Despite having an adequately planned blood supply, 2 female and 1 male patients resulted in total necrosis of the skin island (Figure 3). Six patients among 102 patients $(5.9 \%)$ demonstrated total or partial skin necroses. It is important to know that $5 \%-7 \%$ of patients receive the major blood supply to the entire pectoralis major muscle through the inferior pectoral artery [18]. The PMMF technique does not, therefore, guarantee 100\% success, probably due to the variation of the blood supply to the muscle.

Modified techniques of the PMMF with longer pedicle have been reported and some emphasized that there was no significant difference in the incidence of the flap necrosis and/or post-operative complications, regardless of either method if the flap was transferred above or under the clavicle [19].

After the pectoral is major muscle is incised, thoraco-acrominal vessels can be traced close the branching point of the subclavian artery. It is possible, therefore, to transfer the flap $3-5 \mathrm{~cm}$ more than the Aryan's procedure $[20,21]$. The under clavicular approach of the pro- 
cedure requires meticulous tissue dissection, thinning of the flap in order to pass it under the clavicle. Consequently it takes rather prolonged operative time and skill. Other than experienced plastic surgeon, an ear-nosethroat surgeon or an oral surgeon is reluctant to choose this approach.

The PMMF technique is shown difficult tobe performed without postoperative complications, particularly in female patients. After the retrospective analysis of the complications, Twenty in 102 patients $(19.6 \%)$ had some postoperative complications in the present study, which was slightly less than previously reports (Table 3) [8-12].

\section{Conclusion}

The "workhorse", another name of the classical PMMF, can be easily employed frequently for the head and neck reconstruction. However, the surgeon must be well aware of the fact that this procedure has minor complications.

\section{REFERENCES}

[1] S. Ariyan, "Further Experiences with the Pectoralis Major Myocutaneous Flap for the Immediate Repair of Defects from Excisions of Head and Neck Cancers," Plastic and Reconstructive Surgery, Vol. 64, No. 5, 1979, pp. 605612.

[2] V. R. Ramakrishnam, W. Yao and J. P. Campana, "Improved Skin Paddle Survival in Pectoralis Major Myocutaneous Flap Reconstruction of Head and Neck Defects," Archives of Facial Plastic Surgery, Vol. 11, No. 5, 2009, pp. 306-310. doi:10.1001/archfacial.2009.67

[3] K. Kiyokawa, Y. Tai, H. Y. Tanabe, et al., "A Method That Preserves Circulation during Preparation of the Pectoralis Major Myocutaneous Flap in Head and Neck Reconstruction," Plastic and Reconstructive Surgery, Vol. 102, No. 3, 1998, pp. 2336-2345. doi:10.1097/00006534-199812000-00010

[4] M. L. Castelli, G. Pecorari, G. Succo, et al., "Pectoralis Major Myocutaneous Flap," European Archives of OtoRhino-Laryngology, Vol. 258, No. 10, 2001, pp. 542-545. doi:10.1007/s004050100389

[5] R. A. Dedivitis and A. V. Guimaraes, "Pectoralis Major Myocutaneous Flap in Head and Neck Cancer Reconstruction," World Journal of Surgery, Vol. 26, No. 1, 2002, pp. 67-71. doi:10.1007/s00268-001-0183-4

[6] J. P. Shah, V. Haribhakti, T. R. Loree, et al., "Complications of the Pectoralis Major Myocutaneous Flap in Head and Neck Reconstruction," The American Journal of Surgery, Vol. 160, No. 4, 1990, pp. 352-355. doi:10.1016/S0002-9610(05)80541-0

[7] S. S. Kroll, H. Goepfert, M. Jones, et al., "Analysis of Complications in 168 Pectoralis Major Myocutaneous Flaps Used for Head and Neck Reconstruction," Annals of Plastic Surgery, Vol. 25, No. 2, 1990, pp. 93-97. doi:10.1097/00000637-199008000-00003
[8] R. Liu, P. Gullane, D. Brown, et al., "Pectoralis Major Myocutaneouspedicled Flap in Head and Neck Reconstruction: Retrospective Review of Indications and Results in 244 Consecutive Cases at the Toronto General Hospital," The Journal of Otolaryngology, Vol. 30, No. 1, 2001, pp. 34-40. doi:10.2310/7070.2001.21011

[9] A. Milenović, M. Virag, V. Uglesić, et al., "The Pectoralis Major Flap in Head and Neck Reconstruction: First 500 Patients," Journal of Cranio-Maxillofacial Surgery, Vol. 34, No. 6, 2006, pp. 340-343. doi:10.1016/i.jcms.2006.04.001

[10] J. N. Mclean, G. W. Carlson and A. Losken, "The Pectoralis Major Myocutaneous Flap Revisited. A Reliable Technique for Head and Neck Reconstruction," Annals of Plastic Surgery, Vol. 64, No. 5, 2010, pp. 570-573.

[11] J. G. Vartanian, A. L. Carvalho, S. M. Carvalho, et al., "Pectoralis Major and Other Myofascial/Myocutaneous Flaps in Head and Neck Cancer Reconstruction: Experience with 437 Cases at a Single Institution," Head Neck, Vol. 26, No. 12, 2004, pp. 1018-1023. doi:10.1002/hed.20101

[12] D. S. Schneider, V. Wu, et al., "Indications for Pedicledpectoralis Major Flap in a Free Tissue Transfer Practice," Head Neck, Vol. 34, No. 8, 2012, pp. 1106-1110.

[13] K. Matsunaga, K. Mori, S. Asamura, et al., "Swallowing Function in Patients Who Underwent Hemiglossectomy and Reconstruction with a Pectoralis Major Myocutaneous Flap," Journal of Japanese College of Surgeons, Vol. 33, No. 6, 2008, pp. 829-836.

[14] K. Matsunaga, K. Kawanishi, N. Iosgai, et al., "Serial Changes in Swallowing Function in a Case of Dysphagia after Jejunal Reconstruction of the Cervical Esophagus: A Case Report," Esophagus, Vol. 4, No. 1, 2007, pp. 47-51. doi:10.1007/s10388-006-0105-5

[15] H. Rikimaru, K. Kiyokawa, K. Watanabe, et al., "New Method of Preparing a Pectoralis Major Myocutaneous Flap with a Skin Paddle That Includes the Third Intercostal Perforating Branch of the Internal," Plastic and Reconstructive Surgery, Vol. 123, No. 4, 2009, pp. 12201228. doi:10.1097/PRS.0b013e31819f2967

[16] S. S. Kroll, G. R. Evans, D. Goldberg, et al., "A Comparison of Resource Costs for Head and Neck Reconstruction with Free and Pectoralis Major Flaps," Plastic and Reconstructive Surgery, Vol. 99, No. 5, 1997, pp. 1282-1286.

[17] H. Rikimaru, K. Kiyokawa, Y. Inoue, et al., "Three-Dimensional Anatomical Vascular Distribution in the Pectoralis Major Myocutaneous Flap," Plastic and Reconstructive Surgery, Vol. 115, No. 5, 2005, pp. 1342-1352. doi:10.1097/01.PRS.0000156972.66044.5C

[18] Y. Ide, "Anatomical Study of the Vascular Distribution in the Pectoralis Major and Its Surrounding Tissue-Especially of the Pectoral Branch of the Thoracoacromial Artery," Archives of Oral Biology, Vol. 37, No. 4, 1995, pp. 255-275. doi:10.2330/joralbiosci1965.37.255

[19] C. J. Kerawala, J. Sun, Z. Y. Zhang, et al., "The Pectoralis Major Myocutaneous Flap: Is the Subclavicular Route Safe?" Head Neck, Vol. 23, No. 10, 2001, pp. 879884. doi:10.1002/hed.1127 
[20] W. I. Wei, K. H. Lam and J. Wong, "The True Pectoralis Major Myocutaneous Island Flap: An Anatomical Study," British Journal of Plastic Surgery, Vol. 37, No. 4, 1984, pp. 568-573. doi:10.1016/0007-1226(84)90151-6

[21] J. H. Palmer and A. G. Batchelor, "The Functional Pec- toralis Major Musculocutaneous Island Flap in Head and Neck Reconstruction," Plastic and Reconstructive Surgery, Vol. 85, No. 3, 1990, pp. 363-367.

doi:10.1097/00006534-199003000-00004 